\title{
Current trends in land subsidence of the North- Central part of Poland using DInSAR technique
}

\author{
H. Rajaoalison ${ }^{1}$, D. Knez ${ }^{2}$ \\ ${ }^{1}$ AGH University of Science and Technology, Department of Drilling and Geoengineering \\ ${ }^{2}$ Faculty of Drilling, Oil and Gas; al. Mickiewicza 30, 30-059 Krakow, Poland
}

\begin{abstract}
The gradual change in the Earth's surface elevation is known as land subsidence and it happens due to natural causes related to geological activities, such as sinkholes, or induced causes related to human activities, such as mining activities, or both. The historical records of land subsidence show that it is mainly related to human activities with damages of more than billions of dollars every year. This paper shows the current trends of land subsidence case of the North-Central part of Poland using the Differential Interferometric Satellite Aperture Radar (DInSAR) technique. That region is known as the extension of the oil and gas reservoir of the Baltic Sea and one of the most populated areas in Poland. This technique uses SAR data images from the sentinel-1A mission of the same area, taken on April 25, 2018 and April 26, 2020, in order to measure the surface changes between these time intervals. Thus, a two-year land subsidence map of that region has been created, with maximum subsidence of $-85 \mathrm{~mm}$. There is no significant subsidence in the production area, but information on the population supports the alleged reasons for such subsidence, namely the infrastructure growth and the need for water resources. Besides, most of the occurred subsidence in the concerned area is concentrated in big cities such as Gdansk and Gdynia. Such result is very important for policymakers, especially concerning the sustainable development goals
\end{abstract}

\section{Introduction}

Land subsidence is the gradual change of the Earth's surface due to natural or induced or both causes. Land subsidence typically occurred when a large amount of fluid had been withdrawn from the underground, while the overburden weight above the reservoir is relatively the same or even increased due to some infrastructures on the surface and, therefore, results in compaction [1,2]. There are couples of historical records of land subsidence related to human activities, such as the one that happened in the Goose Creek oil field in 1925, where the entire Gaillard Peninsula parcel was submerged by water [3]. Also, a land subsidence of $14 \mathrm{~m}$ due to high demand for groundwater and geothermal water production, close to high-density populated areas, was recorded at Wairakei geothermal field in New Zealand [4]. In addition, the rapid industrial growth associated with the development of the urban area caused a recorded land subsidence of 20 to $200 \mathrm{~cm}$ in Jakarta between 1982 and 1997. Growing cities cause significant movement of construction materials and influence the overburden stresses. Apart from that, the mining industry 
significantly changes the underground stresses. It is easy to find such cases in the south part of Poland, where coal mines produce large surface damages. Open-pit mines producing coal or other minerals are also a considerable source of stress variations and surface subsidence. Development of new oil and gas resources requires exploration of natural minerals from open pits [5] so the growing petroleum production influences land subsidence in other parts of Earth.

Traditional methods of measuring land subsidence include detailed surveys and tide level gauges using the high precision Global Positioning System (GPS) and tiltmeters. These techniques require a large number of benchmarks and observation points for mapping, accessibility of the area, and are quite costly [6]. However, the geophysical application of SAR is capable to cope with these issues by using electromagnetic waves and take advantage of shifted phases from different observation times of the same antenna position to measure deformations expressed on the surface. High-density spatial mapping of ground deformation associated with tectonic and volcanic activities has been demonstrated $[7,8,9]$. The InSAR is a technique used to map land deformation with high accuracy by using collected radar images of the Earth's surface (Fig. 1). Radar waves (electromagnetic) can penetrate clouds even in a very bad weather conditions, that makes it one of the most effective methods for monitoring ground deformations, such as volcanic evolution, earthquakes, subsidence, etc.. Space agencies in Italy, Germany, Canada, Japan, Korea, Europe, and the USA provide these SAR data images, in which some of them are free for the public, such as the data used in this study [10]. However, one of the best uses of the InSAR is perhaps a better understanding of crust deformation.

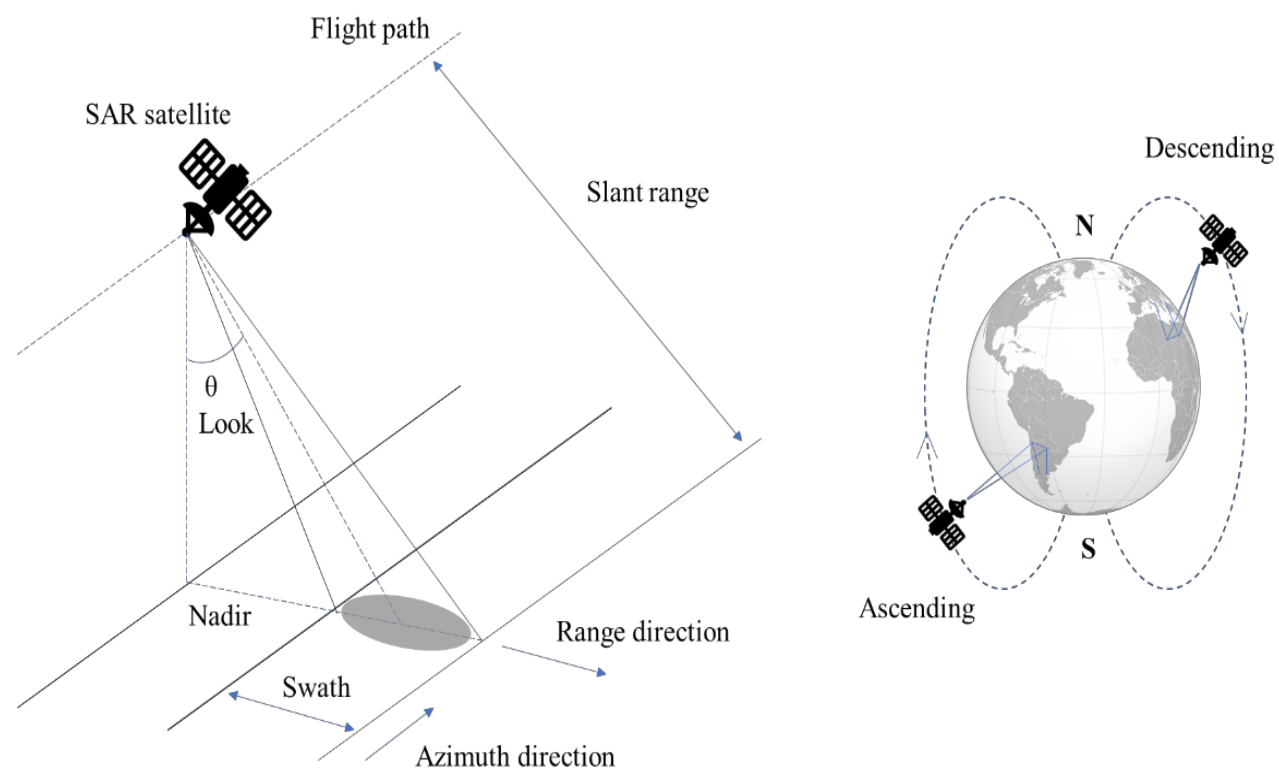

Fig. 1.InSAR data acquisition mode.

Electromagnetic radar waves are emitted from the SAR satellite, travel through the atmosphere, hit the ground, bounce back to space, and are recorded by the same satellite. The echo contains the amplitude and phase. The amplitude includes the return signal strength that is affected by the physical properties of the surface. The distance from the satellite to the ground and its back echoing to the satellite is expressed in the radar wavelength. The phase difference records the time between the two images. By combining or interfering the two waves, amplification or cancellation will occur between the wave 
rays $[11,12]$. Another benefit of the InSAR is the ability to cover a very large spatial area with centimeter to millimeter accuracy, unlike the other techniques that measure only few points $[13,14,15]$. It is then empowers scientists to monitor some specific areas, such as a subsiding area, by producing images of space-time evolution. It is also a very useful technique, especially for remote areas and monitoring a specific place with hazardous conditions, like a volcano or places of explosions.

The aim of this paper is to map the land deformation in the North-Central part of Poland using SAR images taken on April 25, 2018, and April 26, 2020. This area is known as the extension of oil and gas of the Baltic Sea exploration region and one of the most populated areas in Poland.

\section{Methodology}

\subsection{DInSAR}

The DInSAR is one of the InSARtechniques, that uses the information phase from two or more SAR images to obtain data on the Earth deformation. Interferometric fringes are generated when changes have been registered between two images [16]. Such information is described in the following relationship (Eq. 1):

$$
\phi_{\text {anw }}=\phi_{\text {topo }}+\phi_{\text {disp }}+\phi_{\text {atmo }}+\phi_{\text {noise }}
$$

where $\Phi_{\text {anw }}$ is the unwrapped phase; $\Phi_{\text {topo }}$ is the topographic phase; $\Phi_{\text {disp }}$ is the phase change due to the movement of the pixel in the satellite line-of-sight direction; $\Phi_{\text {atmo }}$ is the phase equivalent of the difference in the atmospheric retardation between passes; and $\Phi_{\text {noise }}$ is the noise term from the variability of the scattering pixels, thermal noise, and co-registration errors.

The data processing is generally divided into four steps, including co-registration, interferogram generation, phase unwrapping, and geocoding (Fig. 2).

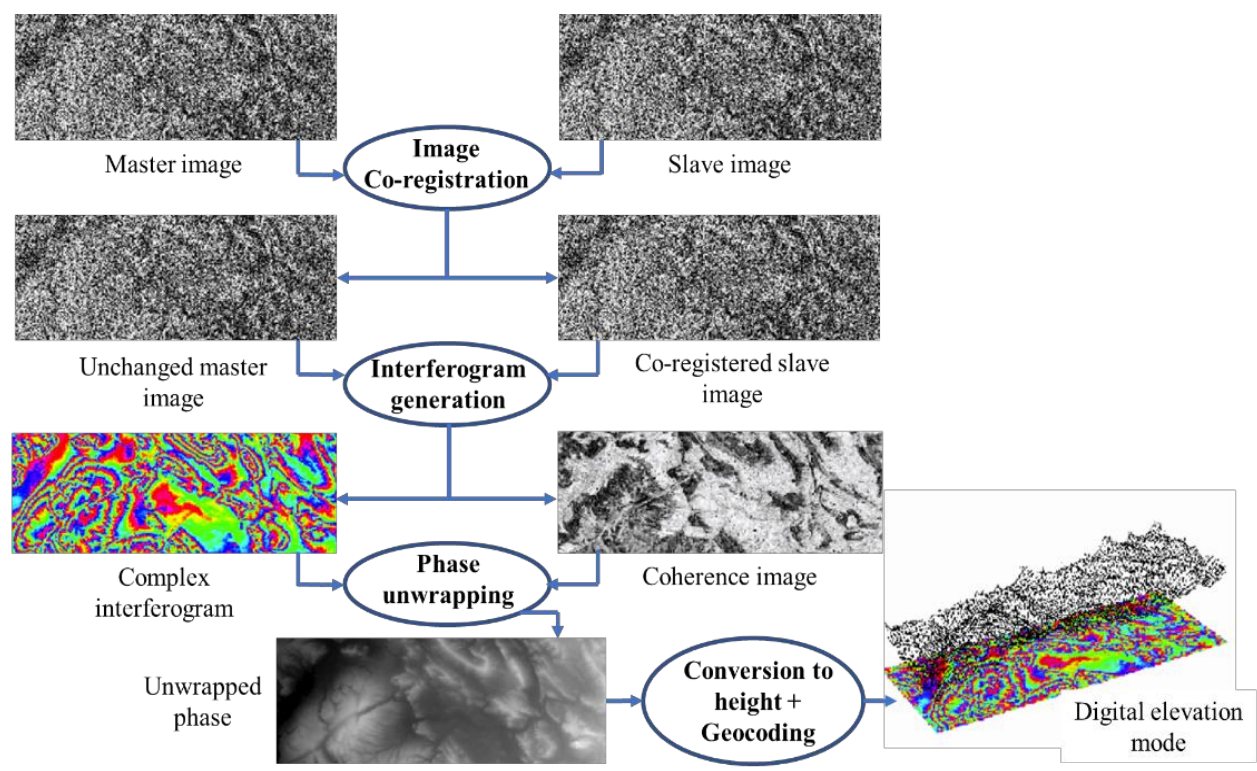

Fig. 2.DInSAR data processing. 
The DInSAR technique consists of comparing two images taken from the same place, before and after an event, such as an earthquake or explosion. Any movement that happens between these time intervals is being recorded and measured using the captured satellite images. Thus, the objective of the DInSAR technique is to obtain the phase changes $\Phi_{\text {disp }}$ and remove the topographic phase $\Phi_{\text {topo }}$. The accuracy obtained with the "two-pass" DInSAR and digital elevation model (DEM) of the shuttle radar topography mission (SRTM) is better than 1:25,000 topographic map. The steps for processing DInSAR data processing steps in SNAP software are described below (Fig. 3).

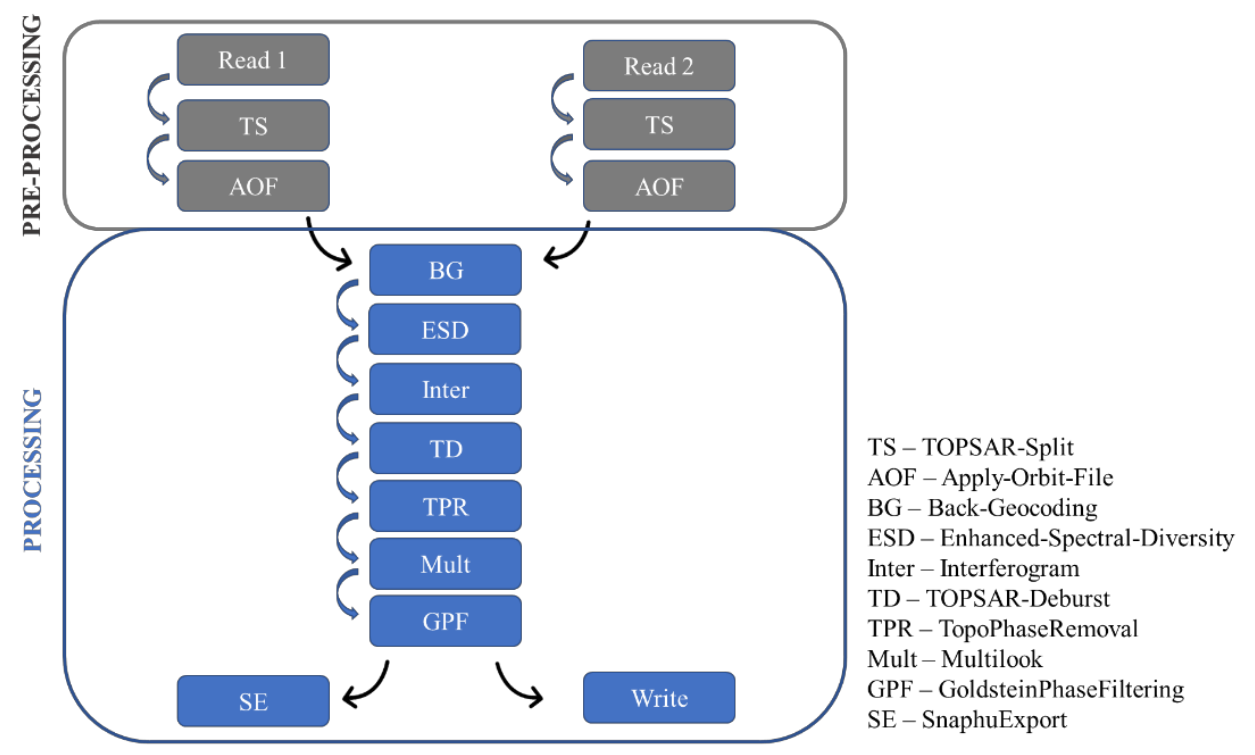

Fig. 3. Data processing steps in SNAP.

\subsection{Study area}

The area of interest is located in the North-Central part of Poland, within the latitude and longitude of $54-55^{\circ} \mathrm{N}$ and $17-19^{\circ} \mathrm{E}$, respectively. It is part of the Polish lowland that covers the eastern part of the NE German-Polish basin, formed during the Precambrian period, including the platform areas of Poland and the Polish sector of the Baltic Sea with an area of $221,000 \mathrm{~km} 2$, covered with sedimentary rocks up to $10-12 \mathrm{~km}$ thick; and the Middle Cambrian formations consisting of fine to medium-grained sandy sediments, with mudstone and claystone intercalations and frequent deformational structures (gravitational flows, bioturbations). The topography of the area is shown in Figure 4. The elevation of the area varies from 0 to $333 \mathrm{~m}$ above the sea level. However, some part close to the shore has a topographic level below $0 \mathrm{~m}$, that could be related to movements of tide near the coast. 


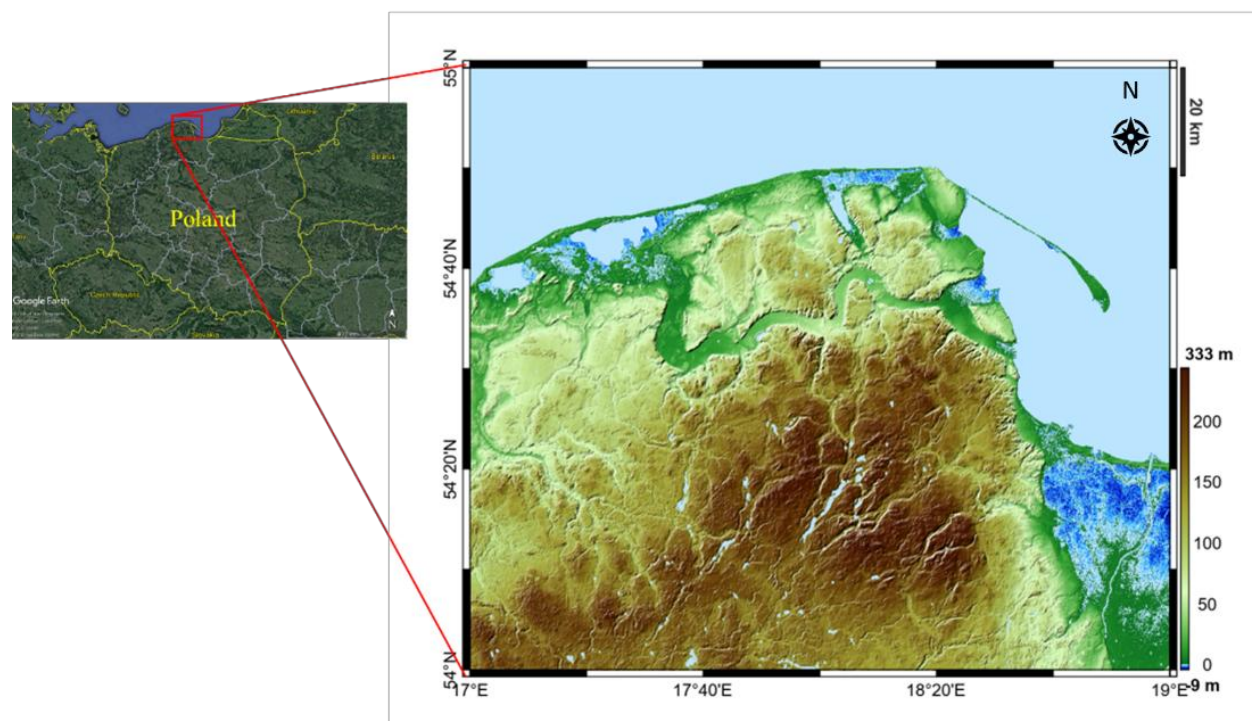

Fig. 4. Topographic profile of the North-Central part of Poland.

Two SAR images from Sentinel-1A SAR scenes, taken on April 25, 2018, and April 26, 2020 , have been used in this study in order to generate the ground deformation of the studied area between these dates, which is nearly two years [17]. The sentinel mission details about these two images are shown in Table 1.

Table 1. Description of the two used SAR images of the concerned area.

\begin{tabular}{ccc}
\hline Mission description & SAR image $\mathrm{n}^{0} 1$ & SAR image $\mathrm{n}^{0} 2$ \\
\hline Sensing date & $2018-04-25$ & $2020-04-26$ \\
Instrument & SAR-C & SAR-C \\
Instrument mode & IW & IW \\
Satellite & Sentinel-1 & Sentinel-1 \\
Mission id & 152640 & 244882 \\
Orbit number & 21619 & 32294 \\
Pass direction & Descending & Descending \\
Polarization & VV-VH & VV-VH \\
Product class & SAR standard L1 & SAR standard L1 \\
Product level & L1 & L1 \\
Product type & SLC & SLC \\
Relative orbit & 22 & 22 \\
Mission type & Earth observation & Earth observation \\
\hline
\end{tabular}

\section{Results and discussion}

Data on the land subsidence of the studied area was generated after sentinel-1 data processing in SNAP software, which is free license software for SAR data processing. 


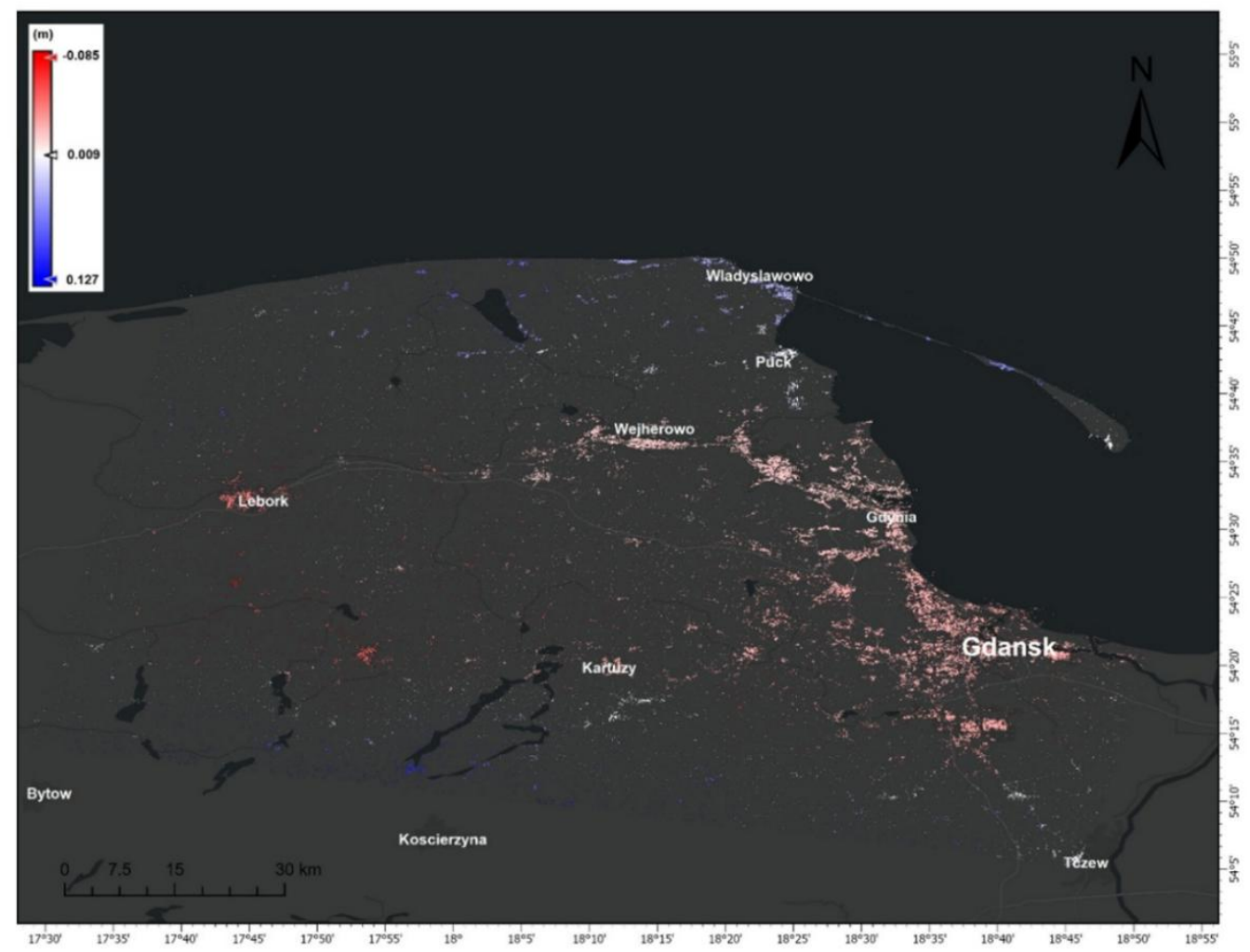

Fig. 5. Land subsidence of the North-Central part of Poland.

The two-year land subsidence of the studied area is presented in Figure 5. The land subsidence of the concerned area generally appears in big cities, such as Gdańsk and Gdynia. The maximum land subsidence of the concerned area was up to $-85 \mathrm{~mm}$; that happened in Lebork town and its surrounding. The north part of the region, where the oil and gas production is located, does not show signs of subsidence; however, the foremost North area, such as in Wladyslawowo, shows slightly uplifted area. Besides that, the area the maximum subsidence is geologically characterized by young sandstones and clays, which are favorable for compaction, especially when large amounts of underground fluids, such as groundwater, have been explored [18]. In addition, the most subsided area is the place of settlement of large cities, which may be associated with the growth of infrastructure. While it is difficult to distinguish the possible sources of land subsidence in this region, population statistics provide information on population growth, which supports the alleged cause of land subsidence in the area, i.e., the infrastructure growth and therefore the increase of in demand of water $[19,20]$.

The deformation on the surface can be related to tectonic or human activities, e.g., natural and induced seismicity. According to Lizurek et al., earthquakes rarely occurred in Poland, especially large earthquakes that could cause damages on the surface. Since 1000, only 100 events were known and recorded in Poland, and those earthquakes occurred in the Southern part. The event of December 3, 1786, with an estimated Richter magnitude of 5.6 is considered as the greatest earthquake that ever happened in Poland. The industrial activities, such as underground mining in the Upper Silesian Coal Basin (USCB) and Legnica GłogowCopper District (LGCD), open-pit mining in "Bełchatow" brown coal 
mine, and reservoir impoundment of Czorsztyn artificial lake near Niedzica hydropower plant, are considered as the main sources of the seismic activities in Poland, especially in the Carpathian Mountains. According to the Polish Seismological Network run by the Institute of Geophysics, Polish Academy of Sciences, the Southern area presents the most active part of Poland, which is characterized by the large number of seismic activities of 3,000 events per year. Besides, the Upper Silesian Seismological Network run by the Central Mining Institute confirmed that around 200 events with magnitude of 2.4 occurred every year and around 55,900 events with magnitude of 1.5 were recorded between 1974 and 2005 [21, 22]. Besides, the copper ore underground exploration, e.g., "Rudna", "PolkowiceSieroszowice", and 'Lubin"' mines, is the source of the anthropogenic seismic activities in the South-West part of Poland, with the annual seismicity events of several hundreds and magnitudes between 0.4 and 4.5 [23, 24]. In contrast to the seismicity in the Southern part, neither natural nor induced seismicity with significant magnitudes has been recorded in the North-Central part of Poland, as it is considered as tectonically stable, and high magnitude events are very rare. Thus, the surface change, related to the seismic activities, whether natural or induced, in the North-Central part of Poland, is insignificant and shall not be monitored, as there is no specific place where it often occurs.

The land subsidence in that region is relatively low comparing to other related worldwide subsidences; however, it shows the efficiency of the satellite monitoring of land deformation, scaled down to millimeter precision. This result is covering a large area, but in the case of a specific place, such as open mining, land subsidence monitoring requires the use of InSAR data combined with other technologies, such as drones data and measurement points data from the high precision GPS.

\section{Conclusions}

This work shows the land subsidence of the North-Central part of Poland using InSAR satellite images. SAR images, taken on April 25, 2018 and April 26, 2020, from the sentinel 1 mission were used to register a two-year land subsidence of the area, where the most subsided area is located in Gdańsk and Gdynia cities, and the maximum recorded land subsidence of up to $-85 \mathrm{~mm}$ was located in the town of Lebork and its vicinity. The geology of the area, as well as the population growth, supports the assumption on the source of such subsidence, which is related to the urbanization and population growth, and consequent growth of demand of water resources. This work is among the first and preliminary land subsidence study cases of the area of concern using SAR data images, which makes it essential, especially for the government and policymakers in terms of sustainable development goals.

\section{References}

1. H.Z.Abidin, H.Andreas, I.Gumilar, Y.Fukuda, Y.E. Pohan, T. Deguchi, Land subsience of Jakarta (Indonesia) and its relation with urban development. Natural Hazards, 59 (3), 1753. (2011).

2. H., Rajaoalison, A., Zlotkowski, G., Rambolamanana, Mechanical properties of sandstone using non-destructive method. Journal of Mining Institute, 241, 113117.(2020).

3. T.L. Holzer, R.L.Bluntzer, Land Subsidence near Oil and Gas Fields, Houston, Texas. Groundwater, 22 (4), 450-459.(1984).

4. R.G.Allis, Review of subsidence at Wairakei field, New Zealand. Geothermics, 29 (45), 455-478. (2000). 
5. D. Knez, A. Calicki, Looking for a new source of natural proppants in Poland. Bulletin of the Polish Academy of Sciences. Technical Sciences, 66 (1).(2018).

6. C.Wang, H.Zhang, Z.Liu, S.Cheng, G.Lu, Satellite interferometric observations ofdisplacements associated with urban subsidence in Suzhou, Eastern China.Changes, 4(3) (2002).

7. H.Fan, K.Deng, C.Ju, C.Zhu, J.Xue, Land subsidence monitoring by D-InSAR technique. Mining Science and Technology (China), 21 (6), 869-872. (2011).

8. S.Atzori, A.Antonioli, C.Tolomei, V.De Novellis, C.De Luca, F.Monterroso, InSAR full-resolution analysis of the 2017-2018 M>6 earthquakes in Mexico. Remote Sensing of Environment, 234, 111461.(2019).

9. I.Ahmad Abir, S.D.Khan, A. Ghulam, S.Tariq, M.T. Shah, Active tectonics of westernPotwar Plateau-Salt Range, northern Pakistan from InSAR observations and seismic imaging. Remote Sensing of Environment, 168, 265-275 (2015).

10. B.M. Popescu, Hydrocarbons of Eastern Central Europe(Springer, 1994).

11. W.D.Barnhart, W.L. Yeck, D.E. McNamara, Induced earthquake and liquefaction hazards in Oklahoma, USA: Constraints from InSAR. Remote Sensing of Environment, 218, 1-12(2018).

12. E.Chaussard, S.Wdowinski, E.Cabral-Cano, F.Amelung, Land subsidence in central Mexico detected by ALOS InSAR time-series. Remote Sensing of Environment, 140, 94-106(2014).

13. TaoLi, JingnanLiu,MingshengLiao, ShaojunKuang, XuLu, Monitoring city subsidence by D-InSAR in Tianjin area. IGARSS 2004. 2004 IEEE International Geoscience and Remote Sensing Symposium, 5,3333-3336 (2004).

14. Y. Guoqing, M.Jingqin, D-InSAR Technique for Land Subsidence Monitoring. Earth Science Frontiers, 15 (4), 239-243(2008)

15. F.Qu, Z.Lu, Q.Zhang, G.W.Bawden, J.-W.Kim, C.Zhao, W.Qu, Mapping ground deformation over Houston-Galveston, Texas using multi-temporal InSAR. Remote Sensing of Environment, 169, 290-306.(2015).

16. F. Grassi, F.Mancini, Sentinel-1 data for ground deformation monitoring: the SNAP StaMPS workflow. Workshop Tematico di Telerilevamento-Bologna. 26.(2019).

17. P.Snoeij, E.Attema, M.Davidson, B. Duesmann, N.Floury, G.Levrini, B. Rommen, B. Rosich, The Sentinel-1 radar mission: Status and performance. 2009 International Radar Conference" Surveillance for a Safer World"(RADAR 2009). IEEE, 1-6.(2009).

18. Story Map Series [online], Available from: http://geologia.pgi.gov.pl/arcgis/apps/MapSeries/index.html?appid=8d14826a895641e 2be10385ef30 5b3c [Accessed 31 Aug 2020].(2020).

19. Gdańsk Population [online], Available from: http://population.city/poland/gdansk/ [Accessed 31 Aug 2020].(2020).

20. Statistical Office in Gdańsk [online], Available from: https://gdansk.stat.gov.pl/en/ [Accessed 31 Aug 2020].(2020).

21. P. Wiejacz, and W. Dębski, Podhale, Poland, earthquake of November 30, 2004. Acta Geophysica, 57 (2), 346-366.(2009).

22. G.Lizurek, Full moment tensor inversion as a practical tool in case of discrimination of tectonic and anthropogenic seismicity in Poland. Pure and Applied Geophysics, 174 (1), 197-212. (2017). 
23. S.Lasocki, Quantitative evidences of complexity of magnitude distribution in mininginduced seismicity: Implications for hazard evaluation. In: The Fifth Int. Symp. onRockbursts and Seismicity in Mines (RaSiM 5)'Dynamic rock mass response to mining. 543-550.(2001).

24. M. Meghraoui, Z. Çakir, Y. Bouhadad, InSAR analysis of a blind thrust rupture and related active folding: the 1999 Ain Temouchent earthquake (M w 5.7, Algeria) case study. Journal of Seismology, 13 (4), 421-432.(2009). 